\title{
Un caso inusual de síndrome de enterocolitis inducida por proteínas alimentarias
} Unusual case of food protein-induced enterocolitis syndrome

\author{
Dra. M. ${ }^{a}$ Teresa Sobrevia Elfau ${ }^{a}$, Dra. Yolanda Aliaga Mazas ${ }^{a}$, Dr. Gonzalo Herraiz Gastesia, \\ Dra. Paula M. ${ }^{a}$ Barberá Pérez ${ }^{a}$ y Dra. Ángela M. Ascaso Matamala ${ }^{a}$
}

\begin{abstract}
RESUMEN
Elsíndrome de enterocolitis inducido por proteínas alimentarias es un síndrome dehipersensibilidad gastrointestinal a alimentos no mediado por inmunoglobulina $\mathrm{E}$, que, en su forma aguda, se manifiesta con vómitos repetitivos, palidez e hipotonía, que puede acompañarse o no de diarrea y producir un cuadro grave de deshidratación y letargia. Una prueba de provocación oral controlada es, en ocasiones, realizada para confirmar el diagnóstico y el tratamiento consiste en la eliminación del alimento causante. Se presenta el caso de un lactante de 3 meses con varios episodios de síndrome de enterocolitis tras la toma de biberón de leche de fórmula de inicio con tolerancia de otra marca comercial.Se encontraron diferencias en los ingredientes desu composición que podrían ser el origen de la sensibilización. Palabrasclave:proteinas alimentarias, enterocolitis, hipersensibilidad a la leche, test de tolerancia oral.
\end{abstract}

\begin{abstract}
Food protein-induced enterocolitis syndrome is a nonimmunoglobulin E mediated gastrointestinal food hypersensitivity that manifests as profuse, repetitive vomiting, pallor and hypotonia, often with diarrhea leading to severe dehydration and lethargy (sepsis-like symptoms) in the acute setting. An oral food challenge is sometimes performed to confirm the diagnosis and treatment consists of elimination of the food trigger(s) from the diet. We report a case of a 3-monthsold infant with several episodes of food protein-induced enterocolitis syndrome after taking infant formula milk with tolerance of another trademark. Differences in the composition of its ingredients could be the cause of the sensitization.

Key words: dietary proteins, enterocolitis, milk hypersensitivity, oral tolerance test.
\end{abstract}

http:/ / dx.doi.org/10.5546/ aap.2017.e247

Cómo citar: Sobrevia Elfau MT, Aliaga Mazas Y, Herraiz Gastesi G, et al. Un caso inusual de síndrome de enterocolitis inducida por proteínas alimentarias. Arch Argent Pediatr 2017;115(4):e247-e250.

a. Hospital Clínico Universitario "Lozano Blesa”, Zaragoza, España.

Correspondencia:

Dra. M. Teresa Sobrevia Elfau: materesas@hotmail.com

Financiamiento: Ninguno.

Conflicto de intereses: Ninguno que declarar.

Recibido: 28-11-2016

Aceptado: 4-4-2017

\section{INTRODUCCIÓN}

El síndrome de enterocolitis inducido por proteínas alimentarias (SEIPA) es una alergia alimentaria no mediada por inmunoglobulina E (IgE) que suele aparecer en el primer año de vida. Su clínica más común son los cuadros de vómitos repetidos, que comienzan entre una y cuatro horas tras la ingestión del alimento causal, acompañados de afectación del estado general y signos de hipotensión por deshidratación, incluso, con aspecto séptico, que ceden lentamente a lo largo de varias horas. Pueden seguirse de una o varias deposiciones diarreicas (acompañadas o no de sangre), pero predominan los síntomas digestivos altos. ${ }^{1}$ Los desencadenantes más frecuentes son la leche de vaca, la soja, el arroz y la avena. El diagnóstico es clínico y puede llegar a ser difícil por la ausencia de sintomatología alérgica típica y el inicio retardado tras la ingesta. Tiene un pronóstico favorable: la mayoría de los niños consiguen la resolución entre los 3 y los 5 años. ${ }^{2}$

Se presenta un caso clínico de SEIPA diagnosticado en nuestro centro.

\section{CASO CLÍNICO}

Lactante de 3 meses nacido a término, alimentado desde el nacimiento con leche de fórmula sin antecedentes personales de interés. Fue evaluado en el Servicio de Urgencias por un episodio de irritabilidad, vómitos repetidos y una deposición blanda en las últimas cuatro horas. Presentaba mal estado general, palidez e hipotonía, que impresionaba shock séptico, sin otros hallazgos al momento de la exploración. Se comenzó un tratamiento con fluidoterapia endovenosa y antibioterapia empírica, que mejoró paulatinamente el estado general y remitió los vómitos. En las horas siguientes, presentó cuatro deposiciones con abundante moco y sangre, por lo que se practicó una ecografía abdominal, que no mostraba alteraciones, y las analíticas realizadas de carácter urgente fueron normales. Se ingresó en planta, donde permaneció en observación. Los síntomas remitieron en las 
primeras 24 horas y, posteriormente, toleró leche de fórmula sin incidencias. Se diagnosticó una posible gastroenteritis aguda infecciosa, aunque los estudios microbiológicos (coprocultivos, virus en heces y hemocultivos) fueron todos negativos. Se suspendió la antibioterapia al tercer día y se otorgó el alta hospitalaria. A las pocas horas del alta, acudió nuevamente a Urgencias por haber comenzado con otro episodio de vómitos, palidez e hipotonía, que se trató allí con fluidoterapia intravenosa. Los síntomas remitieron en 12 horas y permaneció hospitalizado en observación durante 24 horas más. Los padres lo relacionaron con la toma de un biberón de leche en el domicilio y fue entonces cuando comunicaron un cambio de marca de leche antes del primer episodio y, anteriormente, varios cambios de marca comercial por motivos económicos.

Durante el ingreso, toleró la marca de fórmula de inicio que había tomado los días anteriores en el Hospital. Se comenzó un estudio alergológico, en el que se hicieron pruebas cutáneas intraepidérmicas (prick-test) con los extractos alergénicos leche, caseína, alfa-lactoalbúmina, beta-lactoglobulina y prick-prick con varias marcas de leche de fórmula de inicio (incluida la relacionada con los episodios) con resultados negativos.

Además, se realizó un estudio de IgE específica in vitro (InmunoCAP ${ }^{\circledR}$ ) a leche de vaca y sus fracciones, con resultado negativo. Se diagnosticó que el lactante padecía SEIPA sobre la base de la historia clínica, la exploración física durante los episodios y las pruebas complementarias realizadas. $^{3}$

Ante la posibilidad de tratarse de un caso de SEIPA no por proteínas de leche de vaca, sino por hipersensibilidad a algún componente de esa marca comercial, transcurrido un mes del segundo ingreso hospitalario, se decidió realizar un test de provocación oral controlada en medio hospitalario para confirmar la sospecha diagnóstica. Al tratarse de una técnica de riesgo, se informó a los padres y se les solicitó la firma de un consentimiento informado. La prueba se llevó a cabo bajo supervisión médica, ingresado en el Hospital con acceso endovenoso. Se utilizó un envase nuevo de la marca comercial sospechosa, y presentó, a los 180 minutos de una dosis total acumulada de 100 $\mathrm{ml}$ (se fraccionó en 3 tomas con intervalos de 30 minutos), vómitos repetidos, mal estado general con palidez cutánea, importante irritabilidad inicial y posterior letargia, por lo que se interpretó como prueba positiva ${ }^{4}$ (Tabla 1) y se trató con fluidoterapia intravenosa. Posteriormente, toleró la marca de fórmula de inicio del Hospital, que fue la única que se recomendó que tomara en su domicilio a partir de entonces.

En la actualidad, tiene 23 meses, es un lactante sano, que ha evitado, por decisión familiar, todos los productos de esa marca comercial y la introducción de la alimentación complementaria a partir de los 6 meses no ha producido ninguna incidencia, con tolerancia de todos los lácteos y derivados.

TABLA 1. Criterios diagnósticos para pacientes que presentan un posible caso de síndrome de enterocolitis inducido por proteinas alimentarias agudo ${ }^{4}$

\begin{tabular}{l|l}
\hline Criterio mayor & Criterios menores \\
\hline $\begin{array}{l}\text { Vómitos transcurridas 1-4 horas de la ingesta } \\
\text { del alimento sospechoso y ausencia de síntomas } \\
\text { clásicos cutáneos o respiratorios mediados por Ig-E. }\end{array}$ & $\begin{array}{l}\text { 1. Un segundo (o más) episodio de vómitos repetidos tras } \\
\text { la ingesta del mismo alimento sospechoso. } \\
\text { 2. Episodio de vómitos repetidos transcurridas 1-4 horas de la } \\
\text { ingesta de un alimento diferente. } \\
\text { 3. Letargia extrema con una reacción sospechosa. }\end{array}$ \\
$\begin{array}{ll}\text { 4. Palidez marcada con una reacción sospechosa. } \\
\text { 5. Necesidad de evaluación en Urgencias por una reacción } \\
\text { sospechosa. }\end{array}$ \\
$\begin{array}{l}\text { 6. Necesidad de soporte fluido intravenoso para tratar una } \\
\text { reacción sospechosa. }\end{array}$ \\
$\begin{array}{l}\text { 7. Hipotensión. } \\
\text { 8. Hipotermia. }\end{array}$
\end{tabular}

Ig-E: inmunoglobulina E.

El diagnóstico de síndrome de enterocolitis inducido por proteínas alimentarias (SEIPA) agudo requiere que el paciente cumpla el criterio mayor $y$, al menos, 3 criterios menores. 


\section{DISCUSIÓN}

El SEIPA es un síndrome de hipersensibilidad gastrointestinal a alimentos no mediado por IgE que suele presentarse en la infancia, generalmente, en el primer año de vida. Proteínas alimentarias activan linfocitos intestinales que elaboran citocinas inflamatorias que producen un aumento de la permeabilidad intestinal, manifestada con un cuadro de vómitos repetidos seguidos o no de diarrea, que puede conducir a un cuadro de deshidratación y letargia. ${ }^{1}$ Los alimentos causantes de esta patología suelen ser la leche de vaca y la soja, pero también cereales, pescado, frutas, huevo, mariscos, entre otros, incluso se ha descrito el probiótico Saccharomyces boulardii. ${ }^{5-8} \mathrm{El}$ arroz es el alimento sólido que produce SEIPA con mayor frecuencia; además, se asocia a reacciones más graves que otros alimentos. $^{9}$

El diagnóstico se basa en la historia clínica, sospecha de alimento causal, exclusión de otras posibles etiologías y, en algunos casos, es necesaria una prueba de provocación oral para confirmar la sospecha diagnóstica, aunque se considera una prueba de riesgo ${ }^{10}$ que debe realizarse en el ámbito hospitalario. En nuestro caso, los padres relacionaron, en el segundo episodio, el cambio de marca de leche con el inicio de los síntomas, pero, tras comprobar la tolerancia de leche durante el ingreso, se decidió realizar una prueba de provocación que confirmara la sospecha. Si únicamente ha ocurrido un episodio, debería considerarse confirmar el diagnóstico mediante una prueba de provocación oral, en especial, al ser tan comunes, en este grupo de edad, los cuadros virales de gastroenteritis aguda. Además, aunque no es un criterio para el diagnóstico, es importante reconocer que las reacciones agudas de SEIPA, típicamente, se resolverán por completo en cuestión de horas en comparación con los cuadros virales de gastroenteritis, que duran varios días. El paciente debe permanecer asintomático y tener un crecimiento normal tras eliminar el alimento de la dieta. ${ }^{4}$

En nuestro paciente, no se realizaron pruebas epicutáneas (atopy patch test) con el alimento sospechoso, ya que, en la actualidad, no se recomienda para el diagnóstico de SEIPA. ${ }^{2}$

El diagnóstico diferencial del SEIPA incluye otros tipos de alergia alimentaria, enfermedades infecciosas, obstrucción intestinal, enfermedad grave por reflujo gastroesofágico, enfermedades metabólicas, neurológicas o cardíacas.
Inicialmente, el tratamiento consiste en eliminar el alimento causal de la dieta y asegurar un plan de actuación y tratamiento para seguir en caso de una exposición accidental.

Los síntomas del SEIPA suelen resolverse en alrededor de cuatro horas. El ondansetrón es un antagonista del receptor de serotonina 5-HT3, utilizado, sobre todo, para profilaxis y tratamiento de náuseas y vómitos producidos por quimioterapia, pero también utilizado comúnmente en gastroenteritis víricas. Hay evidencia de que la administración de ondansetrón corrige los vómitos en 1530 minutos. ${ }^{11}$ En nuestro caso, no se utilizó al tratarse de un lactante menor de 6 meses.

La mayoría de los casos de SEIPA se resuelven a la edad de 3 años, ${ }^{10}$ por lo que se recomienda realizar una provocación oral a los 18-24 meses para comprobar la tolerancia, si no ha habido reacciones recientes. ${ }^{12}$

Nuestro paciente presentó, en tres ocasiones (dos con inicio en el domicilio y una en el Hospital), el cuadro clínico típico de enterocolitis en su forma aguda tras la toma de leche de vaca adaptada para lactantes en los primeros meses de vida. Lo que llamó la atención fue la tolerancia de otra marca comercializada de leche para lactantes. Al comparar la composición de ambas fórmulas, se observó como única diferencia la presencia de aceite de pescado en la fórmula que toleraba y de algas en la marca que producía los síntomas. La industria ha incluido en sus leches para lactantes ingredientes adicionales, como el ácido docosahexaenoico (ADH) y ácido araquidónico (ARA). Estos son ácidos grasos omega 3 y omega 6 , respectivamente, que se encuentran en la leche materna y en ciertos alimentos, como el pescado o el huevo, y que favorecen el neurodesarrollo del lactante. En el caso clínico que se presentó, nuestro paciente toleró la leche enriquecida con ácidos grasos omega 6 procedentes del hongo Mortierella alpina y omega 3 procedentes de aceite de pescado, pero el problema podría encontrarse en los que proceden de aceites de algas, ya que fue la única diferencia encontrada en la composición. $\mathrm{Al}$ no tratarse de una patología mediada por IgE, no se pudo disponer de pruebas de laboratorio que confirmaran nuestra hipótesis.

\section{REFERENCIAS}

1. Nowak-Węgrzyn A, Muraro A. Food Protein-Induced Enterocolitis Syndrome. Curr Opin Allergy Clin Immunol 2009;9(4):371-7.

2. Nowak-Wegrzyn A, Jarock-Cyrta E, Moschione Castro APB. Food Protein-Induced Enterocolitis Syndrome. J Investig 
Allergol Clin Immunol 2017;27(1)1-18.

3. Khanna N, Patel K. FPIES: Reviewing the Management of Food Protein-Induced Enterocolitis Syndrome. Case Rep Pediatr 2016;2016:1621827.

4. Nowak-Węgrzyn A, Chehade M, Groetch M, et al. International Consensus Guidelines for the Diagnosis and Management of Food Protein-Induced Enterocolitis Syndrome-Executive Summary. J Allergy Clin Immunol 2017. [Epub ahead of print].

5. Zapatero Remón L, Alonso Lebrero E, Martín Fernández E, et al. Food-Protein-Induced Enterocolitis Syndrome caused by fish. Allergol Immunopathol (Madr) 2005;33(6):312-6.

6. Bruni F, Peroni DG, Piacentini GL, et al. Fruit proteins: another cause of Food Protein-Induced Enterocolitis Syndrome. Allergy 2008;63(12):1645-6.

7. Hsu P, Mehr S. Egg: a frecuent trigger of Food ProteinInduced Enterocolitis Syndrome. J Allergy Clin Immunol 2013;131(1):241-2.
8. HwangJB, Kang KJ, Kang YN, etal.Probioticgastrointestinal allergic reaction caused by Saccharomyces boulardii. Ann Allergy Asthma Immunol 2009;103(1):87-8.

9. Mehr SS, Kakakios AM, Kemp AS. Rice: a common and severe cause of Food Protein-Induced Enterocolitis Syndrome. Arch Dis Child 2009;94(3):220-3.

10. Katz Y, Goldberg MR, Rajuan N, et al. The prevalence and natural course of Food Protein-Induced Enterocolitis Syndrome to cow's milk: A large-scale, prospective population-based study. J Allergy Clin Immunol 2011;127(3):647-53.e1-3.

11. Holbrook T, Keet CA, Frischmeyer-Guerrerio PA, et al. Use of ondansetron for Food-Protein-Induced Enterocolitis Syndrome. J Allergy Clin Immunol 2013;132(5):1219-20.

12. SichererSH. Food Protein-Induced Enterocolitis Syndrome: case presentations and management lessons. J Allergy Clin Immunol 2005;115(1):149-56. 